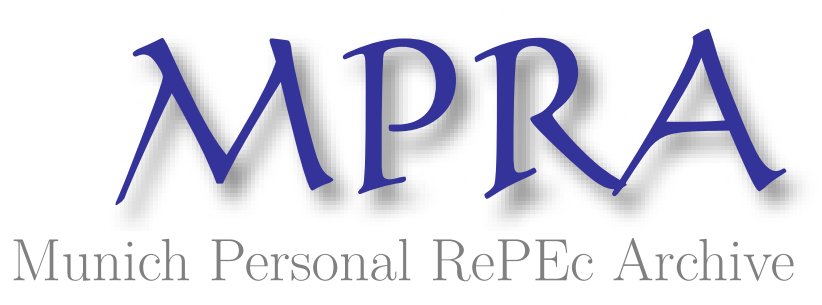

\title{
Changes in inflation persistence prior and subsequent to the subprime crisis: What are the implications for South Africa?
}

Phiri, Andrew

Department of Economics, Finance and Business Studies, CTI Potchefstroom Campus, North West, South Africa

11 April 2016

Online at https://mpra.ub.uni-muenchen.de/70645/

MPRA Paper No. 70645, posted 13 Apr 2016 06:50 UTC 


\title{
CHANGES IN INFLATION PERSISTENCE PRIOR AND SUBSEQUENT TO THE SUBPRIME CRISIS: WHAT ARE THE IMPLICATIONS FOR SOUTH AFRICA?
}

\author{
A. Phiri \\ Department of Economics, Finance and Business Studies, CTI Potchefstroom Campus, \\ North West, South Africa
}

\begin{abstract}
The appropriateness of the inflation targeting regime as a policy framework for the South African Reserve Bank (SARB) continues to be a furiously debated topic for both academics and policymakers alike. In this study, we approach this debate by examining whether there have been any changes in the persistence of the inflation process for periods prior and subsequent to the global financial crisis. By effect, our study attempts to answer the question of whether inflation targets have been successful in controlling inflation rates in the face of unanticipated financial crisis. Indeed, our empirical results indicate that persistence in the inflation process has decreased in periods subsequent to the subprime crisis, and yet this has been accompanied by decreases in economic growth and unchanged high levels of unemployment. Our study ultimately suggests that given the current status of the economy, inflation may be required to be lowered to close-to-zero levels which will have to be accompanied with higher levels of economic growth, separate macroeconomic policies which specifically target unemployment and a change in domestic real interest rates.
\end{abstract}

Keywords: Inflation persistence; inflation targeting; global financial crisis; monetary policy; South Africa; sub-Saharan Africa (SSA).

JEL Classification Code: C22; C23; E31; E51. 


\section{INTRODUCTION}

Price stability can unanimously be deemed as the crux of monetary policy conduct worldwide and a number of Central Banks have demonstrated their commitment to price stability by explicitly adopting inflation targeting frameworks, with the South African Reserve Bank (SARB) having followed pursuit in 2002. The rationale for monetary authorities to be concerned with keeping inflation low is not difficult to pinpoint in the literature and the adverse costs of high inflation include the depression of savings and investment, the distortion of relative prices, increasing the income or poverty gap as well as the distortionary effects which inflation exerts on unindexed accounting measures and taxes (Veller and Ellyne, 2011). Nonetheless, much debate has been cast on the appropriateness of the inflation targeting regime for the South African economy and whether inflation targeting as a monetary policy tool has taken priority over other existing macroeconomic problems such as low economic growth, high unemployment rates and other labour market deficiencies. Furthermore, it has also been argued that many elements of domestic inflation are beyond the control of the Reserve Bank thus resulting in the unnecessary manipulation of short-term interest rates at the cost of improved output and employment levels. This has led to a number of economists and structuralist groups having questioned the usefulness of the inflation targeting regime and whether the framework should be abandoned in favour of other polices frameworks such as output-growth or employment targeting frameworks (Epstein, 2003).

One useful method of evaluating the efficiency of the SARB's inflation targeting regime is to examine the extent to which the Reserve Bank has been able to control prevailing rates of inflation rate. In this sense, the amount of persistence detected in the inflation process serves as a convenient measure of the extent of control which Central Bank's exert over the inflation process. And in particular, the sum of autoregressive coefficients (SARC) from an estimated autoregressive (AR) function of inflation currently stands as the benchmark for measuring intrinsic persistence in the inflation process. When the SARC is found to be below unity, then inflation is deemed not to be persistent such that the time series exhibits equilibrium reverting behaviour. On the other hand, if SARC of the inflation process is above unity, then inflation is considered as being persistence such that any shock to the inflation process will result in a permanent shift of inflation from its steady state equilibrium. For instance, Rangasamy (2009) compares the SARC of the CPI inflation in South Africa for periods prior to and subsequent to the implementation of the inflation targeting framework and finds that the 
adoption of inflation targets have improved the Reserve Bank ability to control domestic inflation. On the other hand, Phiri (2016) finds that the 3-6 percent target range currently being employed by the SARB has proved to more difficult to control in comparison to inflation rates outside this range. Furthermore, a study by Mourelle et. al. (2011) insinuates that the optimal level of inflation in South Africa lies close to a zero percent rate thus advocating for lower inflation targets. Conversely, Khadaroo (2005) contends that the optimal level of inflation lies at a much higher rate of 14 percent therefore arguing for an extension on the upper target limit of the current inflation target range.

In considering the contradictory nature presented in former empirical works, our study adds a different dimension to the existing literature by examining whether, under the inflation targeting regime, there has been a change in the levels of persistence in the inflation process for periods prior to and subsequent to the unforeseen global financial crisis of 2007 to 2008 . This, by effect, will indicate as to whether there has been an altercation in the Reserve Bank's ability to control inflation rates in light of the global financial crisis. Currently, there exists an abundance of empirical research concerning the effects which the financial crisis has exerted over various monetary policy pass-through effects and, to the best of our knowledge, no research has been conducted concerning the extent on which the crisis has altered the ability for monetary authorities to control domestic inflation rates. Such findings could prove valuable to the current body of knowledge on the inflation targeting debate. In supplementing our research we also provide an overview of the relationship between i) inflation and economic growth, ii) inflation and unemployment, and iii) inflation and interest rates, for the South African economy for periods before and after the financial crisis yet under the inflation targeting era. In turn, this will enable us to draw a more concrete economic outlook relative to our analysis of persistence found in the inflation process.

The rest of the paper is organized as follows. The next section provides an overview of the current implementation of inflation targeting in South Africa. The third section provides an overview of the relationship between inflation and certain aspects of the macroeconomy, namely; economic growth, unemployment and interest rates. The fourth section presents the empirical data, the empirical model as well as the empirical results. The study is concluded in the fifth section of the paper in the form of policy recommendations and directions for future research. 
AFRICA?

In February 2000, former South African minister of finance, Mr. Trevor Manuel, announced the South African Reserve Banks (SARB) intention to adopt an inflation targeting monetary policy framework as a formal monetary policy regime, with set targets to have been met in 2002. The Monetary Policy Committee (MPC) of the Reserve Bank was formed shortly afterwards and has since been delegated the responsibility of implementing the inflation targeting framework in South Africa. Currently the MPC is headed by the Reserve Bank governor and the remaining members of the committee include the Deputy Reserve Bank governors, the adviser to the Reserve Bank governor and the head of the research and statistics division at the SARB. At it's inception, the MPC would host meetings every 6 weeks and this was rescheduled to quarterly meetings (once every three months) and currently the MPC meets every 6 weeks. At these meetings, the MPC discuss macroeconomic developments in the country and after projecting inflation forecasts for up to 24 months, the MPC takes a decision on its policy stance. The MPC then communicates its decision through an announcement at a media conference and also through a release of press conference. The Reserve Bank also releases a quarterly bulletin, the Monetary Policy Review, which is easily available online and further hosts a number of Monetary Policy Forums countrywide to discuss inflationary and macroeconomic developments to an invited audience.

Initially, the Reserve Bank targeted CPIX inflation index, which is a measure of the consumer price index (CPI) less mortgage interest costs. However, since 2009, the Reserve Bank began targeting the CPI index and is still currently targeting this particular index. The inflation range was set at 3 to 6 percent from the onset, which was temporarily changed to 3 to 5 percent in 2005, but has since been reverted back to its original range of 3 to 6 percent range. The Reserve Bank uses the repurchase or 'repo' rate as it's short term policy instrument in keeping inflation within its set target range of 3 to 6 percent. The system of repurchase agreements is intended to influence lending and credit behaviour by commercial banks which then feeds into the rest of the macroeconomy. When inflation breaches the upper target level of 6 percent, then the Reserve Bank will raise the repo rate, thereby making it more difficult for Commercial Banks to obtain money from the Reserve Bank. This, in turn, will lower investment and consumption activities in the macroeconomy, thus lowering aggregate demand and ultimately placing downward pressure on inflation. In the case of actual inflation breaching 
the lower target level of 3 percent, the Reserve Bank will reverses it's actions by lowering interest rates, which will lower the commercial bank rates, and this will increase aggregated demand through increased consumption and investment which ultimately raises the inflation rate.

\section{INFLATION AND THE MACROECONOMY IN SOUTH AFRICA}

\subsection{An overview of inflation and economic growth in South Africa}

Academically, the dynamic relationship between inflation and economic growth can be traced back to the seminal paper of Tobin (1965) who speculated that an increase in money supply (and hence inflation) would, through money-capital substitution effects, lead to increases in capital accumulation and hence economic growth. Early empirical studies conducted for empirical data collected before the mid-1960's tended to support this claim. Shortly afterwards, Sidrauski (1967) challenged Tobin's (1965) notion of a positive inflationgrowth relationship by developing a dynamic growth model in which inflation affects nominal variables but does not exert any influence over real variables such as unemployment and economic growth. However, both claims by Tobin (1965) and Sidrauski (1967) were short lived following periods of stagflation in the early 1970's through to the early 1980's dominantly caused by oil supply shocks as well as the fall of the Bretton Woods system of exchange rates. Thereafter emerged the neo-classical growth models of Stockman (1981), Greenwood and Huffman (1987), Cooley and Hansen (1989) in which inflation decreases economic agents welfare through labour-leisure substitution effects whilst in the endogenous growth models of Lucas and Stokey (1987) and McCallum and Goodfriend (1987) inflation acts as a tax on the returns to human and physical capital thus ultimately reducing the steadystate economic growth.

However, it was the initial study of Fisher (1993) which speculated that inflation varies across different wide-bands, with the effects of inflation on economic growth gradually becoming magnified as one moved up inflation width bands. To put it more precisely, Fisher specified three inflation width-bands in his study, namely, 0 to 15 percent, 15 to 40 percent and 40 percent and above, and found that the most adverse effects of inflation on economic growth emerge when inflation is above 40 percent and above whereas the inflation rates with the least adverse effects where those found in the range of 0 to 15 percent. Similar sentiments were 
shared in the study of Bruno and Easterly (1995) who found that the most adverse effects of inflation on economic growth occur when inflation is above 40 percent. Nonetheless, it was the seminal paper of Sarel (1996) which first brought about the question of the precise level of inflation at which the adverse effects of inflation begin to manifest itself on economic growth. Sarel (1996) concluded on a threshold level or an optimal inflation rate of 8 percent for the data. Later on, Khan and Senhadji (2001) developed on Sarel (1996) by segregating their panel data into industrialized and developing economies and found that developed economies have an inflation threshold in the region of 1 to 2 percent whereas for developing economies this threshold is between 11 and 12 percent. By implication, the results of the study of Khan and Senhadji (2001) suggest discrepancies in inflation behaviour between developed and developing economies, and more specifically indicating that developing countries have a higher tolerance of inflation in comparison to developed countries.

Following the study of Khan and Senhdaji (2001), a plethora of studies have been conducted for individual countries to examine the threshold level of inflation at which the effects of inflation on economic growth begin to switch. For the case of South Africa, four studies have been conducted and these studies are summarized below in Table 1 .

Table 1: Inflation thresholds and economic growth in South Africa: Summary of empirical evidence

\begin{tabular}{ccc}
\hline Author & Time period & Inflation threshold \\
\hline Phiri (2010) & $2000-2010$ & $8 \%$ \\
Leshoro (2012) & $1980-2010$ & $4 \%$ \\
Morar (2012) & $1983-2010$ & $9.5 \%$ \\
Adusei (2012) & $1965-2010$ & $7 \%$ \\
\hline
\end{tabular}

What is implied in these studies is that the inflation threshold represents the level at which the perverse effects of inflation begin to emerge on economic growth and this is assumingly the level at which the upper margin of the inflation target range should be placed. Notably, none of the studies reported in Table 1 confers to the upper target margin of the 
SARB's current inflation target (i.e. 6 percent). In fact, with the sole exception of the study of Leshoro (2012), the remaining studies suggest that the upper margin of the SARB's inflation target should be set at a higher rate. However, in paying close attention to the graphical representation of inflation and economic growth movements, as shown in Figure 1, one observes that during the periods subsequent to the adoption of the inflation targeting framework yet before the global financial crisis of 2008, levels of inflation were relatively low (and frequently breaching the lower 3 percent boundary of the inflation target) and this was accompanied with relatively high levels of economic growth which lie in the range of 3 to 6 percent. On the other hand, after the financial crisis, inflation was generally contained within the upper 6 percent boundary, and this was accompanied by lower rates of economic growth which were slightly held below 3 percent. We thus arrive at two conclusions based on this review. Firstly, the empirical evidence provided thus far contradicts the data plotted in Figure 1. We attribute this contradiction to the outdated econometric techniques used the in the previous empirical studies as summarized in Table 1. Secondly, the ideal combination of low inflation rates and relatively high economic growth occurred in periods before the sub -prime crisis when inflation was relatively below the lower boundary of the inflation target.

Figure 1: Inflation and economic growth in South Africa (2003:q1-2016:q1)

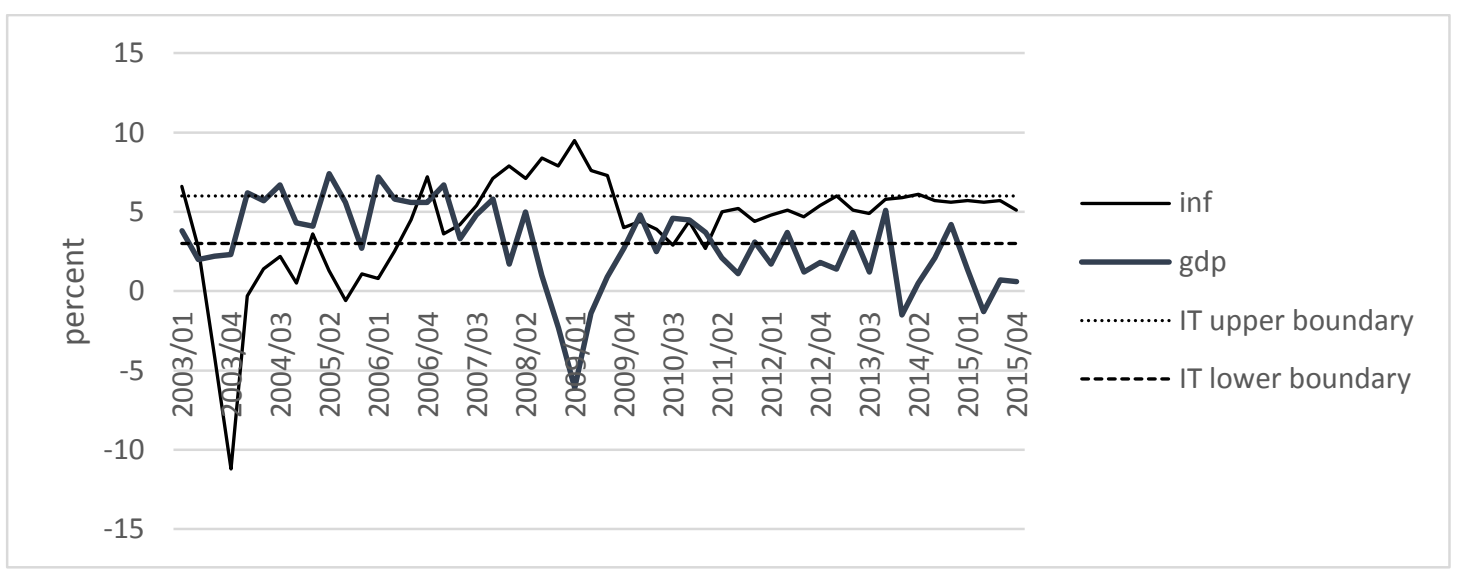

\subsection{An overview of inflation-unemployment correlation in South Africa}

In 1958, AW Phillips wrote an influential paper which found a significantly negative relationship between wage price inflation and the unemployment rate in the United Kingdom for data spanning from 1861 to 1957 . This negative relationship has been formally known as the 'Phillips curve' and forms an important component of standard macroeconomic theory in 
being representative of the 'twin evils' of any macroeconomy. Since then, there have emerged four versions of the Phillips curve specification, namely;

I. Traditional Phillips curve specification which specifies inflation as a function of the unemployment rate.

II. New Classical Phillips curve (NCPC) which specifies inflation as a function of inflation inertia and a measure of macroeconomic demand pressures in the form of the output gap (i.e. deviation of output growth from its 'potential output').

III. New Keynesian Phillips curve (NKPC) which specifies inflation as function of inflation expectations and macroeconomic demand pressures. Macroeconomic pressures can be represented through either the output gap or via some form of marginal costs (i.e. unit labour costs).

IV. Hybrid New Keynesian Phillips curve (HNKPC) which specifies inflation as function of inflation inertia, inflation expectations and macroeconomic demand pressures.

Each of these Phillips curve specifications has been investigated for South Africa and a summary of the previous empirical studies is summarized in Table 2 below: 
Table 2: Phillips curve in South Africa: Summary of empirical evidence

\begin{tabular}{|c|c|c|}
\hline Phillips curve model & Empirical studies & Findings \\
\hline Traditional Phillips curve & $\begin{array}{l}\text { Gallaway et. al. (1970), } \\
\text { Hume (1971), Truu et. al. } \\
\text { (1975), Strebel (1976). }\end{array}$ & $\begin{array}{l}\text { Studies generally found } \\
\text { evidence of an inflation- } \\
\text { unemployment trade-off. }\end{array}$ \\
\hline NCPC & $\begin{array}{l}\text { Pretorius and Small (1994), } \\
\text { Nell (2000), Hodge (2002, } \\
\text { 2009), Fedderke and } \\
\text { Schaling (2005), Burger and } \\
\text { Marnikov (2006), Phiri } \\
(2016) .\end{array}$ & $\begin{array}{l}\text { Studies found that NCPC is } \\
\text { incompatible with South } \\
\text { African data. }\end{array}$ \\
\hline NKPC & $\begin{array}{l}\text { Burger and Du Plessis } \\
\text { (2013), Phiri (2016). }\end{array}$ & $\begin{array}{l}\text { Studies found that strict } \\
\text { forward looking NKPC does } \\
\text { not fit South African data. }\end{array}$ \\
\hline HNKPC & $\begin{array}{l}\text { Burger and Du Plessis } \\
\text { (2013), Malikane (2014), } \\
\text { Phiri (2016). }\end{array}$ & $\begin{array}{l}\text { Studies found that HNKPC } \\
\text { best fits South African data. }\end{array}$ \\
\hline
\end{tabular}

As can be observed from Table 2, the first group of studies found prominent evidence of a Traditional Phillips curve specification for South African data. However, these earlier studies have been criticized on the basis of using unemployment data which did not account for unemployment statistics from previously-disadvantaged groups in the country. Furthermore, periods of stagflation (i.e. periods of high inflation accompanied with high unemployment) experienced in the early 1970's through to the early 1980's discarded these earlier results as being spurious. The second group of studies, which were then conducted under the NCPC framework, took advantage of using the output gap as more reliable measure of macroeconomic demand pressures. However, these studies failed to produce a significant fit for the Phillips curve with most the regression coefficient estimates proving to be insignificant in these studies. Similarly, we also find that the third group of studies, which have been conducted under the NKPC framework, produced insignificant regression coefficients 
regardless of whether the output gap or unit labour costs are used as the driving variable in the system. It is ultimately the HNKPC model which effectively provides a fit for South African data with the output gap being the most suitable measure of demand pressure. All-in-all, the empirical studies of various forms of Phillips curve specifications in South Africa, do not support the notion of a direct relationship between inflation and unemployment, and this can be easily seen in Figure 2 below, in which there are no visible co-movement behaviour between inflation and unemployment in periods before and after the global financial crisis within the inflation targeting era.

Figure 2: Inflation and unemployment in South Africa (2002-2015)

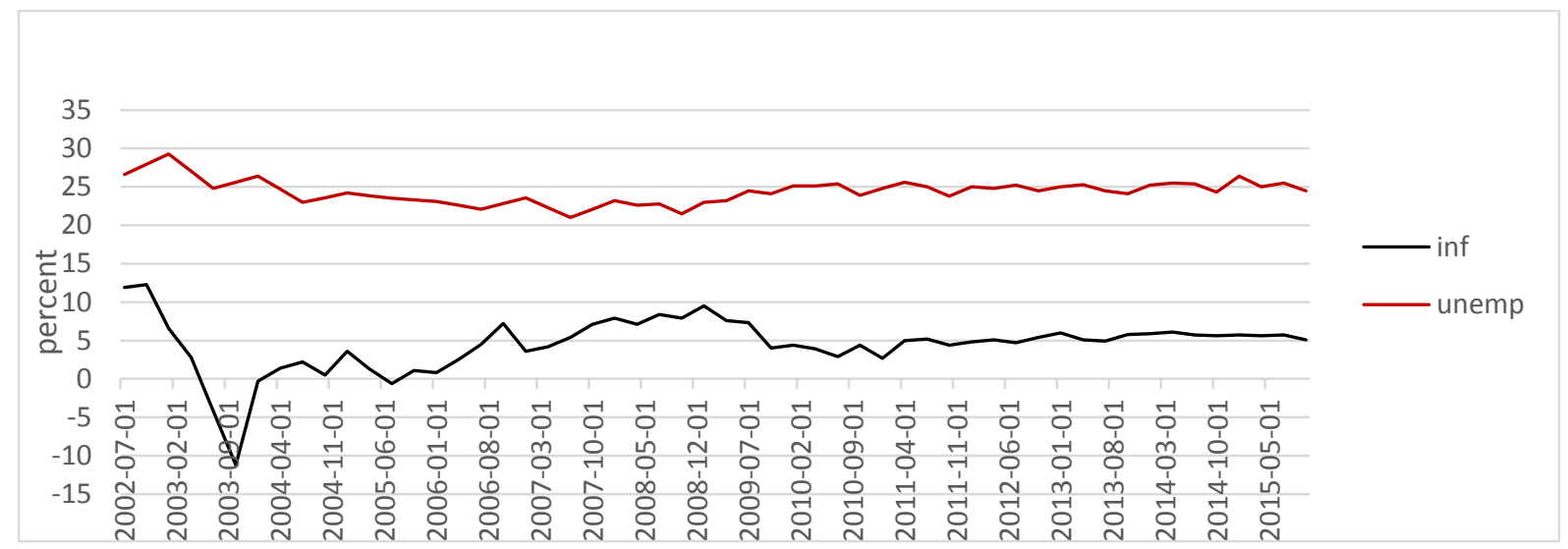

\subsection{An overview of inflation and interest rates in South Africa}

The relationship between inflation and interest rates is referred to as the Fisher hypothesis or the Fisher effect following the works of Fisher (1921) who predicted a one-forone movement between inflation expectations and nominal interest rates which would leave real interest rates untampered. So far, the studies of Mitchell-Innes et. al. (2007) as well as that of Phiri and Lusanga (2011) are the only studies which have been conducted for the case of South Africa, with these empirical results of these studies being summarized in Table 3 below. 
Table 3: Fisher effect in South Africa: Summary of empirical Evidence

\begin{tabular}{lll}
\hline Author & Time period & Findings \\
\hline Mitchell-Innes et. al. (2007) & 2000: 01-2005:05 & No short-run effect and \\
& partial long-run effects. \\
Phiri and Lusanga (2011) & 1980:01-2011:04 & No short-run effects if the \\
& difference between short- \\
& term interest rates and \\
& inflation is in the range of \\
& 1.15 and 2.88 percent. \\
& No long-run Fisher effects if \\
& the difference between long- \\
& term nominal interest rates \\
& and inflation is in the range \\
& of 0.10 and 4.92 percent. \\
\hline
\end{tabular}

In elaborating on the previous empirical studies summarized in Table 3, one must first distinguish between the methodological approaches used in both studies. Firstly, the study of Mitchell et. al. (2007) finds no short run linear cointegration between short-term nominal interest rates and inflation expectations while finding long-run cointegration effects with a cointegration vector coefficient of 0.23 . On the other hand, the study of Phiri and Lusanga (2011) employ threshold cointegration techniques to establish that nominal interest rates and inflation expectations are only cointegrated outside a certain width band and their cointegration vector is established at a value close to unity (i.e. 1.19). Moreover, Phiri and Lusanga (2011) find that when the short-term real interest rate (the difference between shot-term nominal interest rates and inflation expectations) is within a range of 1.15 and 2.88 , then a cointegration Fisher effect does not hold. In examining Figure 3, which is a graphical representation of the co-movement of the repo rate and inflation, it can be observed that in periods prior to the financial crisis there was a considerate gap between inflation and the repo rate (or a larger real interest rate). As can be further observed during these periods that changes in the repo rate result in a change in the inflation rate of somewhat a similar magnitude after approximately 10 to 12 months. However, in periods subsequent to the financial crisis, we observe a lower real interest rate (i.e. lower gap between inflation and the repo rate) and for most of the time the 
movement between inflation and interest rates was somewhat distorted, with the exception of periods when the real interest rate was negative (2011:06 to 2014:10), in which decreases and increases in the repo rate, correspondingly resulted in similar magnitude increases and decreases in the inflation rate appro1ximately 9 to 12 months afterwards. As of 2015:02, the gap between inflation and interest rates lies within a range in which the Fisher effect is invalid, and hence we can expect insignificant (and at best slow) pass-through effects from interest rates to inflation in future periods.

Figure 3: Inflation and the repo rate in South Africa (2003:q1-2016:q1)

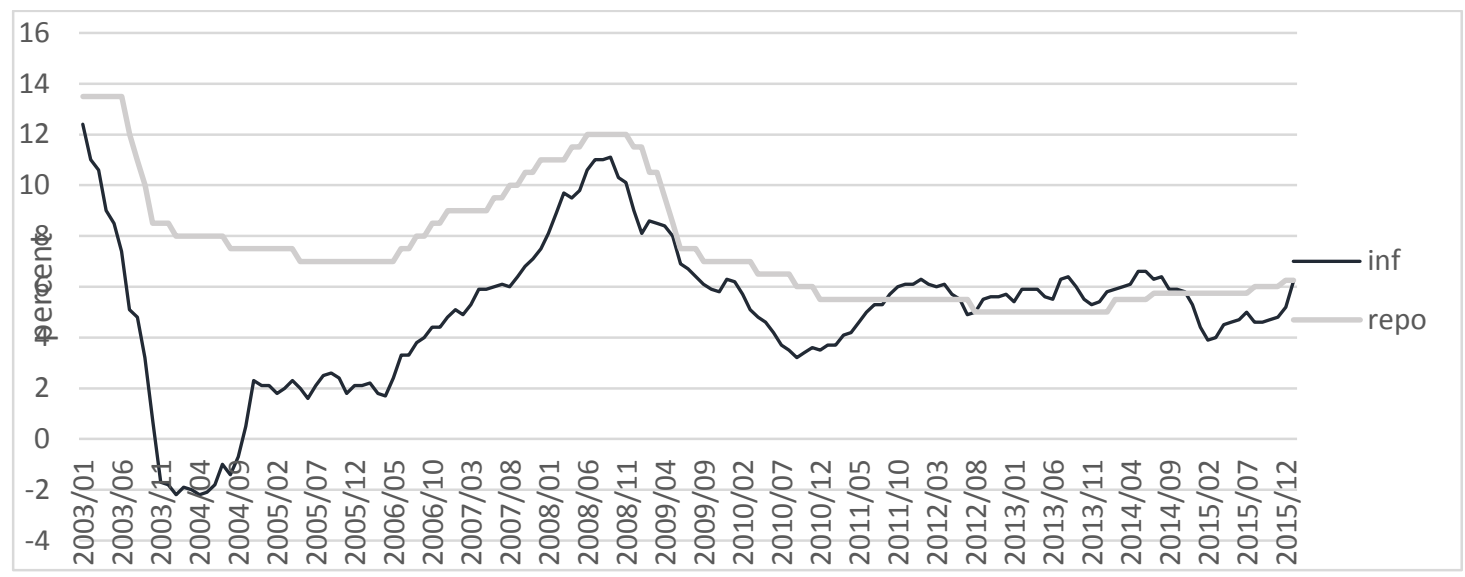

4 DATA AND EMPIRICAL ANALYSIS

\subsection{Data and empirical framework}

Our empirical study uses 5 measures of monthly collected of aggregated inflation from 2003:01 to 2016:01 collected from the South African Reserve Bank (SARB) online database. The inflation data includes i) total CPI: memorandum item (memo) ii) total CPI: Administrative prices (admin) iii) total CPI (total) iv) total consumer prices of commodities (goods) v) total consumer prices of services (services). For empirical purposes we further segregate our empirical data into subsets, the first corresponding to periods prior the peak of the subprime crisis (2002:01 to 2008:06) and the second corresponding to periods subsequent to the subprime crisis (2008:07 to 2016:01). As a means of measuring inflation persistence, we follow in pursuit of Rangasamy (2009) and estimate the follow uni-variate autoregressive (AR) process of an inflation time series $\left(\pi_{\mathrm{t}}\right)$ : 
$\pi_{t}=\beta_{1} \pi_{t-1}+\beta_{2} \pi_{t-2}+\beta_{3} \pi_{t-3}+\ldots+\beta_{p} \pi_{t-p}+\varepsilon_{t}$

From regression (1), inflation persistence $(\rho)$ is measured as the sum of autoregressive (SARC) coefficients i.e.

$\rho=\beta_{1}+\beta_{2}+\beta_{3}+\ldots+\beta_{p}$

And the decision rules for evaluating persistence in the inflation process are as follows. If $\rho \geq 1$, then inflation is persistent and behaves like a difference-stationary, unit root process, whereas if $\rho<1$, then inflation is not persistent and behaves as a stationary, mean-reverting process. As a supplementary measure to our empirical analysis we also estimate inflation persistence using a panel AR model of inflation, with the five different measures of aggregate inflation being collectively treated as the panel time series data. In the spirit of Bleaney and Francisco (2005), the panel AR model of inflation is specified as:

$\pi_{t}=\phi_{1} \pi_{t-1}+\phi_{2} \pi_{t-2}+\phi_{3} \pi_{t-3}+\ldots+\phi_{p} \pi_{t-p}+\varepsilon_{t i}+u_{i}+v_{i t}$

Where $e_{i}$ represents inflationary fixed effects, $u_{t}$ is a time fixed effect and $v_{i t}$ is the idiosyncratic error term. Measures of inflation are indexed by $i$ whilst time is indexed by $t$. As before, inflation persistence is measured by the summation of the coefficients $\phi$, as:

$\rho=\phi_{1}+\phi_{2}+\phi_{3}+\ldots+\phi_{p}$

And once again the decision rules remain as before i.e. $\rho \geq 1$, inflation is persistent and if $\rho<1$, then inflation is not persistent. Estimation of the panel models is conducted using three estimators, namely; OLS, fixed effects and random effects techniques. Furthermore, the estimation of the panel models is evaluated are conducted through i) an F-test which tests the null hypothesis of a fixed effects model against the alternative of an OLS regression ii) Hausman chi-square test of the null of random effects against the alternative of a fixed effect model iii) the Breusch-Pagan tests of the null of random effects against the alternative of an OLS regression.

\subsection{Empirical results}


Table 4 reports the empirical estimates of the SARC for the 5 individual measures of aggregate inflation in South Africa whereas Table 5 reports the SARC estimates for the 5 measures of aggregate inflation when collectively treated as panel data. As can firstly be observed from Table 4, inflation persistence appears to be higher in periods before the subprime crisis while persistence in the inflation process significantly decreases in periods subsequent to the financial crisis. Moreover, the SARC estimates for periods before the subprime crisis exceeds unity, thus implying a highly persistent inflation process whereas in periods after the crisis, the SARC estimates are quite below unity, thus implying less persistence existing in the time series. This finding holds true for all aggregate measures of inflation with the sole exception of the CPI administrative prices, of which the SARC is lower for periods prior to the subprime crisis. However, given the overriding evidence of lower SARC estimates in periods after the financial crisis in comparison to periods before the crisis, it is safe to conclude that the Reserve Bank has maintained a higher control of the inflation rate in periods after the financial crisis.

In turning our attention to the results report in Table 5 for our panel analysis, we find that for the panel model estimating inflation persistence before the crisis $\left(\rho_{\text {pre }}\right)$ and after the crisis $\left(\rho_{\text {post }}\right)$, the fixed effects estimators are the most appropriate estimators since these panel modes whereas for the panel model covering the entire inflation targeting period, the OLS regression estimators suffice. In closely analysing the reported results, we are able to draw similar conclusions to those derived from Table 4, except for the estimation results reported in Table 5 indicate that whilst inflation persistence was lower in periods after the financial crisis, both SARC estimates from before and after the subprime crisis where below unity. The later finding thus implies that the Reserve Bank has been able to control inflation in both sub periods, albeit being easier to control inflation in periods after the global financial crisis. Also based on the SARC estimates reported in both Tables 4 and 5, we can further conclude that a majority of the inflation persistence found for the entire period after the adoption of the inflation targeting periods can be attributed to the sub-period before the global financial crisis. 
Table 4: Individual time series estimates of inflation persistence measures in South Africa

\begin{tabular}{cccc}
\hline Inflation measure & $\rho_{\text {pre }}$ & $\rho_{\text {post }}$ & $\rho_{\text {full }}$ \\
\hline memo & $1.31[18]$ & $0.81[19]$ & $0.93[16]$ \\
admin & $0.89[18]$ & $0.90[18]$ & $0.88[14]$ \\
total CPI & $1.11[16]$ & $0.84[18]$ & $0.95[16]$ \\
total commodities & $1.19[13]$ & $0.79[16]$ & $0.93[19]$ \\
total services & $1.04[18]$ & $0.74[18]$ & $0.93[20]$
\end{tabular}

Note: $\rho_{\text {pre, }} \rho_{\text {post }}$ and $\rho_{\text {full }}$ denote are the SARC measures for periods before the subprime crisis, for periods after the subprime crisis, and for the entire inflation targeting period, respectively. Optimal lag lengths for AR estimates as selected by AIC are reported in [].

Table 5: Panel estimates of inflation persistence in South Africa

\begin{tabular}{|c|c|c|c|c|c|c|c|}
\hline \multicolumn{5}{|c|}{ Estimators } & \multicolumn{3}{|c|}{ Evaluation tests } \\
\hline & OLS & $\begin{array}{l}\text { Fixed } \\
\text { effects }\end{array}$ & $\begin{array}{l}\text { Random } \\
\text { Effects }\end{array}$ & Decision & $\mathrm{F}$ & $\chi^{2}$ & $\mathrm{LM}_{\mathrm{bp}}$ \\
\hline$\rho_{\text {pre }}$ & 0.98 [17] & 0.97 [17] & 0.97 [17] & $\begin{array}{l}\text { Fixed } \\
\text { effects }\end{array}$ & $\begin{array}{c}0.41 \\
(0.41)\end{array}$ & $\begin{array}{c}2.97 \\
(0.08)^{*}\end{array}$ & $\begin{array}{c}1.23 \\
(0.27)\end{array}$ \\
\hline$\rho_{\text {post }}$ & 0.89 [18] & $0.89[18]$ & 0.89 [18] & $\begin{array}{l}\text { Fixed } \\
\text { effects }\end{array}$ & $\begin{array}{c}1.02 \\
(0.40)\end{array}$ & $\begin{array}{c}94.86 \\
(0.00)^{* * * *}\end{array}$ & $\begin{array}{c}0.13 \\
(0.72)\end{array}$ \\
\hline$\rho_{\text {full }}$ & 0.94 [17] & 0.93 [17] & 0.93 [17] & OLS & $\begin{array}{c}1.18 \\
(0.32)\end{array}$ & $\begin{array}{c}2.05 \\
(0.15)\end{array}$ & $\begin{array}{c}0.05 \\
(0.83)\end{array}$ \\
\hline
\end{tabular}

Note: $\rho_{\text {pre }}, \rho_{\text {post }}$ and $\rho_{\text {full }}$ denote are the SARC measures for periods before the subprime crisis, for periods after the subprime crisis, and for the entire inflation targeting period, respectively. Optimal lag lengths for AR estimates as selected by AIC are reported in parentheses [] whereas the $\mathrm{p}$-values for the evaluation tests are reported in (). 


\section{CONCLUSION}

In this study, we sought to re-evaluate the issue of persistence in the inflation process for South African aggregated monthly data collected from 2003:01 to 2016:01. As a further development of our study, we examined whether there has been a change in persistence for periods before the subprime crisis (2002:01 - 2008:06) and for periods after the crisis (2008:07 - 2016:01). By effect, this is intended to evaluate the control which the SARB has had on inflation in the face of a global financial crisis. Indeed, our empirical results show that there has been less persistence in the inflation process in periods after the global financial crisis, thus highlighting the success which the Reserve Bank has had with respect to controlling inflation in the face of major supply shocks. However, we interpret our empirical results with certain degree of caution as our preliminary overview of the South African macroeconomy indicates that whilst the Reserve Bank may have been able to control inflation at moderate rates of inflation (i.e. after the subprime crisis), with inflation rates barely being kept below the upper 6 percent margin of the inflation target, this has been accompanied with a lower economic growth performance, unchanged high rates of unemployment and relatively low real interest rates. On the other end of the spectrum, when inflation has been at the lower 3 percent margin of the target (i.e. before the subprime crisis), the Reserve Bank has experienced difficulty in controlling inflation, whilst at these low rates, there has been higher economic growth, higher real interest rates and unchanged high rates of unemployment.

So, what is to be learnt from our empirical study? Firstly, we observe that at low, closeto-zero rates of inflation it has been more challenging for the Reserve Bank to control inflation even though it is at these low levels of inflation that higher economic growth rates can be achieved. Secondly, in immediately pursuing these low rates of inflation, it is best that policymakers make use of other macroeconomic policy strategies as opposed to the aggressive manipulation of interest rates which would possible result in undesirably high levels of real interest rates. Thirdly, in the event that inflation rates can be kept at low, close-to-zero percentage points accompanied by high economic growth rates above 6 percent, then it would be advisable for the South African Reserve Bank to follow in pursuit of other Central Banks in developed economies (e.g. European Central Bank (ECB), the Bank of Japan (BOJ) an the US Feds), by adopting a low-to-negative interest rate policy objectives while simultaneously keeping inflation rates low i.e. low real interest rates. We suggest such a monetary policy option 
in view of the non-viability of fixed exchange rate policies which will distort capital flows which are used to finance the current account and the failure of monetary targets whose usefulness has been diminished by a weakened money demand function. Lastly, in suggesting policies which would simultaneously lower unemployment and increase economic growth rates, the study concludes that policymakers in South Africa should place more emphasis on labour market strategies and other structural-related fiscal policies which can be contained within strict measures of fiscal discipline.

\section{REFERENCES}

Adusei M. (2012), "The inflation-growth nexus: estimating the threshold effect for South Africa”, Journal of Money, Investment and Banking, 26, 87-93.

Bleaney M. and Francisco M. (2005), "Inflation persistence and exchange rate regimes: Evidence from developing countries", Economics Bulletin, 6(2), 1-15.

Bruno M. and Easterly W. (1995), "inflation crisis and long-run growth", NER Working Paper No. 5209.

Burger P. and Du Plessis S. (2013), “A New Keynesian Phillips curve for South Africa”, In P. Schaeffer \& E. Koussai (Eds), Econometric methods for analyzing economic development, pp. 30-48, Hershey, Pa.: IGI Global.

Burger P. and Marnikov M. (2006), "The South African Phillips curve: How applicable is Gordon's model?", South African Journal of Economics, 74(2), 172-189.

Cooley T. and Hansen G. (1989), "The inflation tax in a real business cycle model”, American Economic Review, 79, 733-748.

Epstein G. (2003), “Alternatives to inflation targeting monetary policy for stable and egalitarian growth: A brief summary", PERI Working Paper, No. 03-62.

Fedderke J. and Schaling E. (2005), "Modelling inflation in South Africa: A multivariate 
cointegration analysis', South African Journal of Economics, 73(1), 79-92.

Fisher S. (1993), “The role of macroeconomic factors in growth”, Monetary Economics, 32(3), 485-511.

Gallaway L., Koshal R. and Chaplin G. (1970), "The relationship between the rate of change in money wages and unemployment levels in South Africa", South African Journal of Economics, 38(4), 367-373.

Greenwood J. and Huffman G. (1987), “A dynamic equilibrium model of inflation and unemployment", Journal of Monetary Economics, 95(1), 203-228.

Hodge D. (2002), "Inflation versus Unemployment in South Africa", South African Journal of Economics, 70(3), 418-443.

Hodge D. (2009), "Inflation, unemployment and economics growth in South Africa”, South African Journal of Economics, 77(4), 488-504.

Hume I. (1971), "A study of inflation in South Africa”, Oxford Bulletin of Economics and Statistics, 33(4), 223-244.

Khan M. and Senhadji A. (2001), "Threshold effects in the relationship between inflation and growth”, IMF Staff Papers, 48, 1-21.

Leshoro T. (2012), "Estimating the inflation threshold for South Africa", ERSA Working Paper No. 285, May.

Lucas R. and Stokey N. (1987), "Money and interest in a cash-in-advance economy", Econometrica, 55(3), 491-513.

Malikane C. (2014), “A new Keynesian Phillips curve”, Economic Modelling, 43(C), 247-255.

McCallum B. and Goodfriend M. (1987), "Money: Theoretical analysis of the demand for money", NBER Working Paper No. 1892. 
Mitchell-Innes H., Aziakpono M. and Faure A. (2007), "Inflation targeting and the Fisher effect in South Africa: An empirical investigation", South African Journal of Economics, 75(4), 693707.

Morar D. (2012), "Inflation threshold and nonlinearity: Implications for inflation targeting in South Africa", M.Com Dissertation, Rhodes University.

Mourelle E., cuestas J. and Gil-Alana L. (2011), "Is there asymmetric behaviour in African inflation? A non-linear approach", South African Journal of Economics, 79(1), 68-90.

Nell K. (2000), "Is inflation a precondition for faster growth: The South African case", Economics Discussion Paper - University of Kent.

Phiri A. (2010), "At what level is inflation least detrimental towards finance-growth activity in South Africa?", Journal of Sustainable Development in Africa, 12(6), 354-364.

Phiri A. (2016), "Examining asymmetric effects in the South African Phillips curve: Evidence from logistic smooth transition regression models", International Journal of Sustainable Economy, 8(1), 18-42.

Phiri A. (2016), "Inflation persistence and monetary policy in South Africa: Is the 3-6 percent inflation target too persistent", International Journal of Sustainable Economy, 18(2), 111-124.

Phiri A. and Lusanga P. (2011), "Can asymmetries account for the failure of the Fisher effects in South Africa?", Economics Bulletin, 31(3), 1968-1979.

Pretorius C. and Smal M. (1994), “A macro-economic examination of the price formation process in the South African economy", South African Reserve Bank Quarterly Bulletin, 2536, March.

Rangasamy L. (2009), "Inflation persistence and core inflation: the case of South Africa", South African Journal of Economics, 77(3), 430-444. 
Sarel M. (1996), "Nonlinear effects of inflation on economic growth", IMF Staff Papers, 43(1), 199-215.

Sidrauski M (1967), "Rational choice and patterns of growth in a monetary economy", American Economic Review, 57(2), 534-544.

Strebel P. (1976), "On built-in inflation, imported prices and the Phillips curve: A comment", South African Journal of Economics, 44 (4), 285-291.

Stockman A. (1981), “Anticipated inflation and the capital stock in a cash-in-advance economy", Journal of Monetary Economics, 8(3), 387-393.

Tobin J. (1965), “Money and economic growth”, Econometrica, 33(4), 671-684.

Truu M. (1975), "Inflation in the South African economy”, South African Journal of Economics, 43(4), 446-470.

Veller C. and Ellyne M. (2011),"What is the SARB's inflation targeting policy, and is it appropriate?”, MPRA Working Paper No. 42134, August. 